\title{
Evolution of Phosphate Metabolism and the Adaptation of Tibetan Wild Barley to Aluminum Stress
}

\author{
Sheng-guan Cai ${ }^{1}$, Yuqin Huang ${ }^{2}$, Li-yuan $\mathrm{Wu}^{1}$, Dezhi $\mathrm{Wu}^{1}$, Rong $\mathrm{Liu}^{3}$, Meixue Zhou ${ }^{4}$, \\ Guo-ping Zhang ${ }^{5}$, and Zhonghua Chen $^{6}$ \\ ${ }^{1}$ Zhejiang University \\ ${ }^{2}$ Hangzhou Academy of Agricultural Sciences \\ ${ }^{3}$ Western Sydney University - Penrith Campus \\ ${ }^{4}$ University of Tasmania \\ ${ }^{5}$ Affiliation not available \\ ${ }^{6}$ University of Western Sydney
}

May 5, 2020

\begin{abstract}
Aluminum (Al) toxicity in acid soils significantly affects plant growth, agricultural productivity and ecosystem health. Here we investigated plant $\mathrm{Al}$ tolerance from evolutionary physiological, molecular, and ecological perspectives. Genetic similarity and phylogenetic analysis of $\mathrm{Al}$ tolerance-associated gene families showed that many of these were conserved from streptophyte algae to angiosperms, indicating land plants have evolved gradually in adaptation to Al-rich acid soil during plant terrestrialization. In particular, vacuolar phosphate transporter SPX-major facility superfamily (SPX-MFS) and inorganic phosphate (Pi) transporter 1 subfamily (PHT1s) of streptophyte algae showed higher genetic similarity to land plants than chlorophyte algae. PHT1 subfamily exhibited a significant expand during the evolution from streptophyte algae to liverworts and then to eudicots. Moreover, we identified an Al-tolerant Tibetan wild barley accession XZ29, showing high levels of Phosphorus(P)-containing glycolytic intermediates under Al stress. We found a new Al-tolerance mechanism that Al-induced Pi efflux from root elongation zone to chelate rhizosphere $\mathrm{Al}+$ and immobilization of $\mathrm{Al}$ with $\mathrm{P}$ reduce $\mathrm{Al}$ accumulation in barley root cells. These results indicated that Tibetan wild barley has evolved unique $\mathrm{P}$ transport and metabolism for the adaptation to harsh conditions in eastern and southeastern Tibet where acid soils contain high P.
\end{abstract}

\section{Abstract}

Aluminum (Al) toxicity in acid soils significantly affects plant growth, agricultural productivity and ecosystem health. Here we investigated plant Al tolerance from evolutionary physiological, molecular, and ecological perspectives. Genetic similarity and phylogenetic analysis of Al tolerance-associated gene families showed that many of these were conserved from streptophyte algae to angiosperms, indicating land plants have evolved gradually in adaptation to Al-rich acid soil during plant terrestrialization. In particular, vacuolar phosphate transporter SPX-major facility superfamily (SPX-MFS) and inorganic phosphate (Pi) transporter 1 subfamily (PHT1s) of streptophyte algae showed higher genetic similarity to land plants than chlorophyte algae. PHT1 subfamily exhibited a significant expand during the evolution from streptophyte algae to liverworts and then to eudicots. Moreover, we identified an Al-tolerant Tibetan wild barley accession XZ29, showing high levels of Phosphorus(P)-containing glycolytic intermediates under $\mathrm{Al}$ stress. We found a new Al-tolerance mechanism that $\mathrm{Al}$-induced $\mathrm{Pi}$ efflux from root elongation zone to chelate rhizosphere $\mathrm{Al}^{3+}$ and immobilization of $\mathrm{Al}$ with $\mathrm{P}$ reduce $\mathrm{Al}$ accumulation in barley root cells. These results indicated that Tibetan wild barley has evolved unique $\mathrm{P}$ transport and metabolism for the adaptation to harsh conditions 
in eastern and southeastern Tibet where acid soils contain high P.

Key words: acid soil, gene family evolution, Hordeum spontaneum, phylogenetic analysis, phosphate metabolism, phosphate transporters 1. Introduction

Aluminum $(\mathrm{Al})$ is the most abundant metal in Earth's crust and Al toxicity is a major factor limiting crop production especially in acid soil, which cover almost $40 \%$ of the world's arable land (Kochian, Pineros, Liu, \& Magalhaes, 2015). Phosphorus (P) is an important macro-nutrition for all living organisms, and functions as a substrate in many metabolic processes such as glycolysis. P deficiency in soil causes significant stress to plants and limiting global food production (Runge-Metzger, 1995). Inorganic phosphate (Pi) can bind with $\mathrm{Al}$ to format Al-P complex (Zheng et al., 2005). P availability is dramatically reduced in acid soils because it forms sparingly soluble complexes with $\mathrm{Al}$, thus $\mathrm{P}$ deficiency and $\mathrm{Al}$ toxicity usually coexist in acid soils (Kochian, Hoekenga, \& Pineros, 2004). Soil P and Al have significant ecological and evolutionary implication for the evolution of plant nutrient uptake and crop domestication for the adaptation to acid soils (Liang et al., 2013).

Despite the importance of crop Al tolerance for sustainable food production and human health, there is limited investigation on the evolution of plant Al tolerance. Streptophyte algae, the sister lineage of land plants, have gradually evolved and equipped with new innovations in gene families for the adaptation of green plants to terrestrial habitats, including Al-rich acidic soils (Taylor et al., 2000; Nishiyama et al. 2018; Leebens-Mack et al. 2019; Zhao et al. 2019; Wang et al., 2020). Herburger, Remias, \& Holzinger (2016) reported that a streptophyte alga Zygogonium ericetorum (Zygnematophyceae, Charophyta) has evolved the capability of $\mathrm{Al}$ tolerance by binding $\mathrm{Al}$ with pectin-rich parental cell wall matrix, thereby reducing $\mathrm{Al}$ accumulation in unpigmented filaments. It is thus suggested that acquisition of $\mathrm{Al}$ tolerance by modification of cell wall components (Yang et al., 2011; Zhu et al., 2012) may be originated from streptophyte algae. On the contrary, Al-induced organic acids secretion was mostly reported in seed plants, but not in lower plants (Yang, Fan, \& Zheng, 2019) while the vital roles of P in plant nutrition and stress tolerance have been conserved across green plants (Lambers et al., 2015; Prodhan, Finnegan, \& Lambers, 2019). Moreover, key P metabolism, Pi transporters SPX-MFSs (Syg1/Pho81/XPR1 with Major Facilitator Superfamily) and PHT1s (phosphate transporter 1 family) have been implicated to function in plants Al tolerance (Cardoso, Pinto, \& Paiva, 2019; Rae, Cybinski, Jarmey, \& Smith, 2003; Wang et al., 2012; Wang et al., 2015). However, the evolutionary origin of $\mathrm{P}$ metabolism and Pi transporters and their roles in $\mathrm{Al}$ tolerance is still elusive.

Micro-molar concentrations of $\mathrm{Al}^{3+}$ can rapidly inhibit root elongation, leading to reduction of water and nutrient uptake, and biomass production and yield reduction (Jones, Blancaflor, Kochian, \& Gilroy, 2006). Some of the key mechanisms conferring this tolerance include the Al-induced release of organic anions from roots (Ma, Ryan, \& Delhaize, 2001; Sasaki et al., 2004; Wang et al., 2007), the modification of cell wall chemistry to reduce accumulation in the apoplast (Yang et al., 2011; Zhu et al., 2012), and phytohormone mediated inhibition of root growth under Al stress (Yang et al., 2014, Yang et al., 2017). Application of phosphate alleviated $\mathrm{Al}$ toxicity by reducing $\mathrm{Al}^{3+}$ availability and stimulating $\mathrm{Al}$ tolerance genes (Jiang, Tang, Zheng, Lie, \& Chen, 2009; Liang et al., 2013; Sun, Shen, Zhao, Chen, \& Dong, 2008). Immobilization of $\mathrm{Al}$ by $\mathrm{P}$ in the cell wall conferred higher $\mathrm{Al}$ tolerance in buckwheat (Zheng et al., 2005). Although the interactions between $\mathrm{P}$ and $\mathrm{Al}$ in plants have been found (Chen et al., 2012; Du et al., 2009; Liang et al., 2013), the underlying mechanisms are still not fully understood.

The center of barley origin and domestication is in the Fertile Crescent (Nevo, Baum, Beiles, \& Johnson, 1998; Dai et al., 2012), where soils are largely saline with higher pH (IGBP-DIS, 1998). Wild barley in Tibet (Hordeum spontaneum ) is well adapted to the harsh conditions of the Tibetan plateau, where large areas of the soil is acidic and contains high P content (IGBP-DIS, 1998; Wang, Yang, \& Ma, 2008). Tibetan wild barley is one of the progenitors of the modern cultivated barley, possessing a wider genetic diversity and a larger variation to abiotic stress tolerance than cultivated barley (Dai et al., 2012; Dai et al., 2014; Wu et al., 2013; Feng et al., 2020). By screening more than one hundred wild barley genotypes, we identified accessions with similar tolerance to Al toxicity as Dayton, a well-known Al-tolerant cultivar (Cai et al., 2013; Dai et al., 2011). Two novel loci bpb-9458 (Chromosome 2H) and bpb-8524 (Chromosome 7H) were linked with $\mathrm{Al}$ 
tolerance in Tibetan wild barley (Cai et al., 2013). These results suggested that the mechanisms controlling Al tolerance are likely to be different between Tibetan wild barley and modern barley cultivars.

It was thus hypothesized that unique P metabolism and transport facilitate Tibetan wild barley's adaptation to low $\mathrm{pH}$ and high $\mathrm{P}$ soil during the evolution. In this study, we have combined evolutionary bioinformatics (Zhao et al., 2019), metabolomics (Urano, Kurihara, Seki, \& Shinozaki, 2010), confocal microscopy (Klug, Specht, \& Horst, 2011), secondary ion mass spectrometry (SIMS) (Kopittke et al., 2015), and electrophysiology (Newman, 2001) to investigate the Al tolerance mechanisms in Tibetan wild barley. We found that most of Al tolerance-related genes, including genes encoding Pi transporters and glycolysis, were conserved from streptophyte algae to angiosperms. Tibetan wild barley has developed an Al tolerance mechanism based on P-related metabolites and gene expression and phosphate efflux from the root apices to chelate toxic $\mathrm{Al}^{3+}$.

\section{Materials and Methods}

\subsection{Evolutionary bioinformatics}

The protein sequences used in this study were obtained from the National Center for Biotechnology Information (NCBI) (http://www.ncbi.nlm.nih.gov), Ensembl Plants (http://plants.ensembl.org/index.html), the OneKP database (http://www.onekp.com). Candidate protein sequences that satisfied the criteria of E-value $<10^{-5}$ were selected by BLASTP searches (Cai et al., 2017; Chen et al., 2017; Zhao et al., 2019). The similarity among protein sequences and families) was calculated according to the BLASTP results using Arabidopsis as a reference species, and the heatmap was drawn using Excel (Microsoft, USA). The alignment of amino acid sequence was performed using MAFFT. For amino acid alignment, conserved domains of aligned sequences were identified using Gblocks v0.91b (http://phylogeny.lirmm.fr). The best-fitting model of amino acid substitution was tested using IQ-Tree v1.6.8 (http://www.iqtree.org), and LG+G4 was identified as best-fitting model under the Akaike Information Criterion. The maximum likelihood (ML) tree was constructed using FastTree v2.1 (http://www.microbesonline.org/fasttree) and was displayed using iTOL v3.0 (https://itol.embl.de).

\subsection{Plant materials and treatments}

Seeds of two Tibetan wild barley accessions XZ29 (Al-tolerant) and XZ9 (Al-sensitive) (Cai et al., 2013), and a cultivar Dayton (Al-tolerant) were soaked in deionized water for $6 \mathrm{~h}$ at $20{ }^{\circ} \mathrm{C}$ in the dark and then germinated on moist filter papers in an incubator $\left(20 / 14{ }^{\circ} \mathrm{C}\right.$, day/night) for two days. Two-days-old seedlings were hydroponically grown in $0.2 \mathrm{mM} \mathrm{CaCl}_{2}$ solution ( $\mathrm{pH} 4.3$ ). For Al treatment, seedlings were exposed to $5 \mu \mathrm{M} \mathrm{AlCl}$. The solution was renewed every day. The relative root growth, the ratio of root elongation under $\mathrm{Al}$ treatment to control, was used as the indicator of $\mathrm{Al}$ tolerance. Root images were acquired by WinRHIZO and analyzed for total root length and relative total root growth according to Cai et al (2013). In addition, all three genotypes and another Al-sensitive cultivar Franklin (Hossain, Zhou, \& Mendham, $2005)$ were grown on acid soil ( $\mathrm{pH}, 4.3$; exchangeable $\mathrm{Al}, 13.6 \mathrm{mEq} / \mathrm{kg}$ ) collected to confirm their tolerance to acid soil in Launceston, Australia.

\subsection{Analysis of primary metabolites by Gas chromatography-mass spectrometry (GC-MS)}

GC-MS-based strategy was used to determine the metabolome profiles of the roots of two-day-old seedling after $6,12,24,48$ and $72 \mathrm{~h}$ of control and $5 \mu \mathrm{M} \mathrm{Al}$ treatments and subsequent $2,6,12$ and $24 \mathrm{~h}$ of $150 \mu \mathrm{M}$ phosphate addition (Lisec et al., 2006). The samples were analyzed by 7890A/5975C GC-MS equipped with HP-5 capillary column (Agilent, USA). Helium was used as a carrier gas at a flow rate of $1 \mathrm{ml} \mathrm{min}^{-1}$. After injection, the temperature was maintained at $80{ }^{\circ} \mathrm{C}$ for $2 \mathrm{~min}$, followed by $5{ }^{\circ} \mathrm{C}$ per min ramp to $300{ }^{\circ} \mathrm{C}$, and was then set at $300{ }^{\circ} \mathrm{C}$ for $10 \mathrm{~min}$. Mass spectra were recorded with a mass-to-charge ratio of 70 to 600 atomic mass units scanning range. The raw data was processed with AMDIS software (http://chemdata.nist.gov/). The relative metabolite level was calculated as $\log _{2}$ transformed ratio of metabolite concentration under $\mathrm{Al}$ treatment (or P addition) to metabolite concentration under control condition (control was sampled at each time point). Experiments were conducted with four biological replicates.

\subsection{Mineral and inorganic phosphorus concentrations}


The mineral and Pi concentrations in the root tips (the first 10-mm) after 2, 6, 24 and $72 \mathrm{~h}$ of $5 \mu \mathrm{M} \mathrm{Al}$ treatments were determined. $\mathrm{Al}$ and $\mathrm{P}$ concentrations in whole root of 12 Tibetan wild barley accessions after $24 \mathrm{~h}$ of $5 \mu \mathrm{M} \mathrm{Al}$ treatment were also measured to determine their correlations with relative root growth under $\mathrm{Al}$ stress. The Al-treated roots were washed with distilled water for three times, and dried in the oven at 110 ${ }^{\circ} \mathrm{C}$. Dry sample was digested with $\mathrm{HNO}_{3}$ using microwave digestion system Microwave 300 (Anton PAAR, Austria). The mineral concentrations were determined using inductively coupled plasma atomic emission spectrometer (ICP-AES) (Thermo Jarrel Ash, USA). The Pi concentration was determined according to Zhou et al (2008) with some modifications. Approximately $50 \mathrm{mg}$ of fresh root sample was homogenized in $1 \mathrm{ml}$ of $5 \%(\mathrm{w} / \mathrm{v})$ perchloric acid and placed on ice for $30 \mathrm{~min}$. After centrifugation at 10,000 g for $10 \mathrm{~min}$ at $4{ }^{*} \mathrm{C}$, the supernatant was used for Pi measurement.

\subsection{Measurement of citrate in root exudates}

The citrate concentration of root exudate from excised root tips of XZ29, XZ9 and Dayton was determined according to Wang et al (2007). Briefly, twenty 10-mm root tips of two-day-old seedlings were excised and washed for three times with $1 \mathrm{ml}$ of control solution $(200 \mu \mathrm{M} \mathrm{CaCl}, \mathrm{pH} 4.3)$. Treatment solutions (200 $\mu \mathrm{M} \mathrm{CaCl} 2$, $\mathrm{pH} 4.3$, with or without $5 \mu \mathrm{M} \mathrm{AlCl}_{3}$ ) were added and the tubes containing the root tips were incubated at $60 \mathrm{rpm}$ for $2 \mathrm{~h}$ using a platform shaker. Then the solution was collected for citrate measurement according to Wang et al. (2007).

\subsection{PCR and qRT-PCR analysis}

DNA was extracted from leaves of barley seedlings according to Qiu et al. (2011). The target DNA fragment was examined by PCR amplification and agarose gel electrophoresis. The presence of 1-kb insertion to the coding region of HvAACT1 (Fujii et al., 2012) was examined using PCR of full length coding sequences in 110 Tibetan wild barley accessions and Dayton. Gene expression of HvAACT1 in 10-mm root tips of the three barley genotypes was determined after $2 \mathrm{~h}$ of $5 \mu \mathrm{M} \mathrm{Al}$ exposure. The expression of the major glycolysis and Pi transporter genes in 10-mm root tips of XZ29 and XZ9 were also determined after 0.5, 2, 6, 12, and $24 \mathrm{~h}$ of $5 \mu \mathrm{M} \mathrm{Al}$ treatments. RNA was extracted using Tiangen RNAprep Pure Plant Kit (Tiangen, China), and cDNA was synthesized using the Reverse Transcriptase kit (Takara, Japan). Gene expression was determined using SYBR Green Supermix (Bio-Rad, USA).HvBetaTublin was used as a reference gene. The primers are listed in Table S1.

\subsection{Microelectrode ion flux estimation (MIFE)}

Al-induced net fluxes of $\mathrm{HPO}_{4}{ }^{2-}$ were measured from elongation zone of three-day-old barley seedlings using MIFE (Chen et al., 2007). LIX for $\mathrm{HPO}_{4}{ }^{2-}$ was prepared using $\mathrm{N}, \mathrm{N}-\mathrm{Bis}$ (salicylidene)-o-phenylenediamine vanadium (IV) oxide complex (Sigma, Switzerland) as ionophore according to Ganjali, Mizani, \& SalavatiNiasari (2003). The seedling was transferred to a 5-ml Perspex measuring chamber with $2.5 \mathrm{ml}$ MIFE basal solution $\left(500 \mu \mathrm{M} \mathrm{KCl}, 100 \mu \mathrm{M} \mathrm{CaCl}_{2}, \mathrm{pH} 4.3\right)$, one hour prior to flux measurement. Net ion flux measurement commenced in the basal solution for $10 \mathrm{~min}$ and followed by $30 \mathrm{~min}$ in $25 \mu \mathrm{M} \mathrm{Al}{ }^{3+}$ treatment by adding $2.5 \mathrm{ml}$ treatment solution $\left(50 \mu \mathrm{M} \mathrm{AlCl} 3,500 \mu \mathrm{M} \mathrm{KCl}, 100 \mu \mathrm{M} \mathrm{CaCl}_{2}, \mathrm{pH} 4.3\right)$. The average flux in control (0-10 $\mathrm{min})$, transient (11 to $15 \mathrm{~min})$ and steady-state (30-40 min) was calculated.

\subsection{Confocal microscopy}

Al-morin fluorescence in the cross-sections of different root zones was examined according to Klug et al. (2011). The two-day-old plants treated with $5 \mu \mathrm{M} \mathrm{Al}$ for 2, 6, 24, and $72 \mathrm{~h}$ were washed with distilled water to remove hydroponic solution from the root surface, and 10-mm of root tips were excised, and immediately embedded in $5 \%(\mathrm{w} / \mathrm{v})$ low-gelling point agarose (Fluka, Switzerland) at $35^{\circ} \mathrm{C}$. The embedded root tips were sectioned using a razor blade and incubated with $30 \mu \mathrm{M}$ morin (Sigma, USA) for $1 \mathrm{~h}$ under darkness. Confocal imaging of Al-morin fluorescence was performed using a Leica Laser Scanning Confocal Microscope SP5 (Leica Microsystems, Germany) equipped with a $20 \times$ water immersion objective. The excitation wavelength was set at $405 \mathrm{~nm}$, and the emission was detected at 490-510 $\mathrm{nm}$. Images were processed with LAS AF software (Leica Microsystems, Germany) and were quantified using Image J software (NIH, USA). 


\subsection{Secondary ion mass spectrometry (SIMS)}

Roots of two-day-old plants treated with $5 \mu \mathrm{M}$ Al for 2, 6, 24, and $72 \mathrm{~h}$ were excised and fixed in $2.5 \%$ glutaraldehyde and $1.6 \%$ paraformldehyde at $4{ }^{\circ} \mathrm{C}$ overnight, followed by $1 \%$ osmium tetroxide for $2 \mathrm{~h}$. Then, the fixed root samples were dehydrated acetone for 3 times. The root samples were embedded in Spurr resin overnight, and polymerized at $70{ }^{\circ} \mathrm{C}$ for $24 \mathrm{~h}$. Five-micrometer-thick section was cut with Leica RM2165 microtome (Leica, Germany), and placed on the silicon wafer (University Wafer, USA). The element distribution in the cross-section of different root zones was analyzed using SIMS (CAMECA, France) according to Smart et al. (2010). The sample was pre-sputtered with $30 \mathrm{nA} \mathrm{O}_{2}{ }^{+}$beam for $15 \mathrm{~min}$ to remove the potential contaminants on the sample surface, and ion maps of ${ }^{27} \mathrm{Al}$ of root cross-section were acquired using $300 \mathrm{pA}$ $\mathrm{O}_{2}{ }^{+}$beam for $20 \mathrm{~min}$, and ion map of ${ }^{31} \mathrm{P}$ was acquired using $200 \mathrm{pA} \mathrm{Cs}{ }^{+}$beam for $30 \mathrm{~min}$, with a resolution of $256 \times 256$ pixels. SIMS data was analyzed using WinImage 2.0 (CAMECA, France).

\subsection{Statistical analysis}

The significance test and the Spearman correlation were analyzed using SPSS software (IBM Corporation, USA). The images were displayed using Excel (Microsoft, USA) and SigmaPlot v14.0 (Systat Software Inc. USA).

\section{Results}

\subsection{Phylogenetic analysis of Al tolerance-associated genes/ gene families}

In order to investigate the origin of $\mathrm{Al}$ tolerance in plants, we performed the genetic similarity and phylogenetic analysis of Al tolerance-associated predicted protein families (Figure 1; Table S2). multidrug and toxic compound extrusion (MATEs) and aluminum-activated malate transporter (ALMTs) mediate Al-induced organic acid secretions from roots (Sasaki et al., 2004; Wang et al., 2007), showed relatively lower protein sequence similarity among the tested species than other membrane transporters related to $\mathrm{Al}$ tolerance (Figures S1; Table S3). Moreover, Al-tolerance responsive transcription factors such as sensitive to proton rhizotoxicity (STOP1/2), and calmodulin-binding transcription activators (CAMTAs) (Kobayashi et al., 2014; Tokizawa et al., 2015) also showed relatively lower genetic similarity between Arabidopsis and other species and a possible origin from streptophyte algae (i.e. Klebsormidium flaccidum ) (Figure 1; Table S3). Moreover, cell wall modification enzymes, pectin methylesterase (PMEs) and xyloglucan endotransglucosylase/hydrolase (XTHs) (Yang et al., 2008; Zhu et al., 2012) were originated from streptophyte algae, and their numbers increased rapidly in land plants (Table S4). Some phytohormones-related protein families relevant to Al tolerance, such as ARFs (Auxin Response Factor), tryptophan-pyruvate aminotransferase (TAAs), flavin-containing monooxygenase (YUCs), and coronatine insensitive (COIs) (Yang et al., 2014; Yang et al., 2017), were largely absent in algae, but were highly conserved in land plants from hornworts to angiosperms (Figure 1; Tables S2-4).

Glycolysis was reported to provide the energy for plant to tolerate Al stress (Dai et al., 2013). Most of the predicted protein families in glycolysis, except hexokinase (HXKs), were highly conserved in green plants and algae (Figure 1). It is worth noting that predicted protein families of glycolysis $(52 \%-81 \%)$ showed higher average genetic similarity to the Arabidopsis than those in other protein families (26\%-75\%) (Figures 1, S2; Table S2). SPX-MFSs and PHT1s are tonoplast and plasma membrane localized Pi transporters, respectively, which play vital roles in cellular P homeostasis (Rae et al., 2003; Wang et al., 2012; Wang et al., 2015). Importantly, most of predicted protein families/sub-families of the Pi transporters, including PHT1s, PHT2s, PHT3s, PHT4s and SPX-MFSs, were highly conserved in land plants and streptophyte algae (Figure $1)$.

To further investigate the origin and evolution of SPX-MFSs and PHT1s, we performed phylogenetic analysis of their predicted protein sequences in land plants and algae using OneKP database and published genome assemblies (Figures 2a, 2b, S3). The genetic similarity of SPX-MFSs and PHT1s to the reference species Arabidopsis was low in Rhodophyta (34\% and 29\%), Chromista (32\% and $31 \%$ ) and chlorophyte algae (30\% and $32 \%$ ), but it increased significantly in streptophyte algae to $43 \%$ and $56 \%$, respectively (Figure 2c). 
Moreover, genetic similarity of PHT1s in streptophyte algae were closer to the land plants - hornworts, liverworts, mosses, and other plant lineages (Figure 2C; Table S3). Interestingly, the average gene number of PHT1s (but not SPX-MFSs) increased gradually in chromista (1), chlorophyte algae (2), streptophyte algae (3), bryophytes (6), lycophytes (7), ferns (12), conifers (15), and angiosperms (17) (Figure 2d). In addition, the analysis of conserved domains of SPX-MFSs and PHT1s demonstrated high amino acid conservation from streptophyte algae (e.g.Klebsormidium flaccidum ) to angiosperms (Figures S4, S5). Taken together, it is thus suggested that streptophyte algae are likely to be a key transitional clade in the evolution of gene families for the SPX-MFS and PHT1 Pi transporters.

\subsection{Al-tolerant Tibetan wild barley XZ29 differs from Dayton in response to Al}

We then attempted to figure out the roles of evolution of $\mathrm{P}$ metabolism and $\mathrm{P}$ transport for $\mathrm{Al}$ tolerance using barley and other plant species in different experiments. In the short-term field trials, XZ29 and Dayton showed greater tolerance to acid soil than XZ9 and Franklin (Figure 3a). In hydroponic experiments with 5 $\mu \mathrm{M} \mathrm{AlCl}_{3}, \mathrm{XZ29}$ and Dayton also showed greater Al tolerance than XZ9 (Figure 3b). In long-term hydroponic experiments with full nutrition and $0,15 \mu \mathrm{M}$ or $60 \mu \mathrm{M} \mathrm{AlCl} 3, \mathrm{XZ29}$ and Dayton are consistently more tolerant than XZ9 (Figures S6). Tissue analysis following these treatments showed that the Al concentration in roots of XZ9 was approximately 1.5-fold greater than in XZ29 or Dayton (Figure 3c).

One of the major established mechanisms for $\mathrm{Al}$ tolerance in cultivated barley is the citrate efflux from the root apices via the HvAACT1 transporter (Furukawa et al., 2007). Therefore, we measured the Al-dependent citrate efflux from excised root tips of XZ29, XZ9 and Dayton and found that Dayton was the only cultivar to show an Al-activated efflux of citrate (Figure 3d). Furthermore, the constitutive expression of HvAACT1 in Dayton roots was four-fold greater than both of the two Tibetan wild barley accessions and the expression of $H v A C C T 1$ was unaffected by Al treatment in all genotypes (Figure 3e). The higher expression of HvAACT1 in Dayton is known to be caused by a $1 \mathrm{~kb}$ insertion upstream of the HvAACT1 coding region and a PCR marker is available to detect the present or absence of this mutation (Fujii et al., 2012). Our results indicated that the 1-kb insertion was present in Dayton, as expected, but not in XZ29 or XZ9 (Figure 3f). This same marker was used to test another 108 Tibetan wild barley accessions with differing levels of $\mathrm{Al}$ tolerance. Surprisingly, none of these accessions possessed the $1 \mathrm{~kb}$ insertion upstream of HvAACT1 (Table S5). Thus, there is likely to be another mechanism controlling $\mathrm{Al}$ tolerance in X29.

\subsection{Reduction of P-containing glycolytic intermediates in barley and other plant species under Al stress}

We first conducted metabolomics of the root tips of XZ29 and XZ9 under 6-72 $\mathrm{h}$ of Al treatment and identified a total of 52 primary metabolites (Table S6). The temporal changes of these metabolites were measured and analyzed with K-means clustering (Figure 4a). Most of the metabolites in Clusters 1, 2 and 3 showed a gradual decrease during 24-72 h of Al treatment. Interestingly, most of these metabolites belong to the glycolysis pathway and its branches. The decrease in the five P-containing glycolytic intermediates in Cluster 1 (glucose-6-phosphate, Glu-6-P; fructose-6-phosphate, Fru-6-P; 3-phosphoglyceric acid, 3-PGA; 2-phosphoglyceric acid, 2-PGA; phosphoenolpyruvate, PEP) were larger and occurred earlier in XZ9 than in XZ29 (Figure 4a, 4b). Many of the metabolites downstream of glycolysis (inositol, galactinol, galactose, serine, cysteine, leucine, isoleucine, threonine and valine) showed similar patterns in XZ29 and XZ9, but the relative changes were greater in XZ9 than for XZ29, especially at $72 \mathrm{~h}$ (Figures $4 \mathrm{~b}, \mathrm{~S} 7$ ). Moreover, highly significant correlations were detected between the glycolytic intermediates and their downstream metabolites (Figure S8). In order to understand the transcriptional regulation of the glycolysis pathway in barley in response to $\mathrm{Al}$ stress, we examined the expression of key genes in this pathway in XZ29 and XZ9 under $0.5 \mathrm{~h}-24 \mathrm{~h}$ of $\mathrm{Al}$ treatments. The up-regulations of Al-induced expression of most glycolysis pathway genes were found earlier in XZ9 $(6 \mathrm{~h})$ than in XZ29 $(12 \mathrm{~h})$ (Figure $4 \mathrm{~b})$. The opposing trends in gene expression and metabolite levels indicated that the inhibition of glycolysis during $\mathrm{Al}$ stress may not occur at the transcriptional level.

To further investigate whether the response of glycolytic intermediates to Al stress is evolutionarily conserved 
in land plants, we performed additional metabolome analysis in rhizoids of a liverwort (Marchantia polymorpha) and roots of a gymnosperm (Ginkgo biloba), a eudicot (Medicago truncatula), and two monocots (Zea mays and Triticum aestivum ). Al-induced reduction of Glu-6-P and Fru-6-P were observed in roots of the examined plant species, except for the rhizoids of liverwort (Figure 4c). Moreover, Al-induced changes in sucrose, inositol, and threonine were detected in all tested plant species (Figure 4c), indicating an early evolution of these metabolites in $\mathrm{Al}$ response of land plants.

\subsection{Decreased $\mathbf{P}$ causes reduction of P-containing glycolytic intermediates under Al stress}

Because $\mathrm{P}$ is an important substrate in glycolysis, we examined the change of $\mathrm{P}$ and $\mathrm{Pi}$ in root tips in a time course of 2, 6, 24 and $72 \mathrm{~h}$ of Al treatments. $\mathrm{P}$ concentration in the root tips of XZ29 remained relatively constant over $72 \mathrm{~h}$ in $\mathrm{Al}$ treatment, whereas $\mathrm{P}$ levels in XZ9 decreased steadily throughout the treatment reaching $65 \%$ of control levels by $72 \mathrm{~h}$ (Figure 5a). Compared to the Al-free controls, Pi concentration in root tips of XZ29 increased significantly during the first $6 \mathrm{~h}$ of $\mathrm{Al}$ treatment and then returned to control levels between 24 and $72 \mathrm{~h}$ (Figure 5b). By contrast, Pi concentrations in root tips of XZ9 showed no increase after $6 \mathrm{~h}$, but these were decreased to $65 \%$ of controls in $24 \mathrm{~h}$ and then remained stable at this lower level (Figure 5b).

The Al-induced changes of $\mathrm{P}$ and $\mathrm{Pi}$ concentrations showed similar pattern as the changes of glycolytic intermediates, with greater decreases occurring in XZ9 than XZ29 (Figures 4b, 5a, 5b). Also, there were positive correlations between the $\mathrm{P}$ and $\mathrm{Pi}$ concentrations and $\mathrm{P}$-containing glycolytic intermediates (Figure $5 \mathrm{c})$. Thus, we investigated the response of glycolytic intermediates levels to the addition of phosphate (150 $\mu \mathrm{M} \mathrm{KH}_{2} \mathrm{PO}_{4}$ ) after $72 \mathrm{~h}$ in $\mathrm{Al}$ treatment. We found that the metabolites in Cluster 1 increased rapidly in both accessions (Figures 5d, S9; Table S7).

\subsection{Al-induced differential gene expression of root $\mathrm{Pi}$ transporters}

The Al-induced expression of Pi transporter and signaling genes in the root tips of XZ29 and XZ9 further confirmed the physiological results (Figure 6). For instance, Al markedly up-regulated HvSPX-MFS2 by 6 -fold in XZ29 after $0.5 \mathrm{~h}$ and remained higher than control for $6 \mathrm{~h}$. By contrast, expression of HvSPX-MFS2 in XZ9 showed no changes in the first $6 \mathrm{~h}$ and decreased to $50 \%$ of control levels between 12 and $24 \mathrm{~h}$ (Figure 6; Table S8). Moreover, HvPHT1;1 showed a significant increase in expression after $0.5 \mathrm{~h}$ in Al treatment, with significantly higher upregulation in XZ29 (22-fold) than in XZ9 (6-fold). The putative mitochondria Pi transporter gene HvPHT3.1 and HvPHT3.2(Hassler et al., 2012) exhibited a rapid increase of expression after $0.5 \mathrm{~h} \mathrm{Al}$ treatment in both accessions. The expression of HvPHT1;4(Rae et al., 2003) and tonoplast Pi influx gene HvSPX-MFS1 (Liu et al., 2015), the xylem loading Pi transporter gene HvPHO1 (Stefanovic et al., 2011) and the Golgi Pi transporter HvPHT4;6(Hassler et al., 2012) were slightly affected by Al (Figure $6)$.

\subsection{XZ29 shows increased Pi efflux for less Al accumulation in the root elongation zone}

Initial accumulation of $\mathrm{Al}$ in root cells, indicated by Morin staining, occurred largely in the root epidermal cells of the meristem and elongation zone after $2 \mathrm{~h}$, and this increased greatly after $6 \mathrm{~h}$ (Figure S10a-d). The intensity of $\mathrm{Al}$ fluorescence in the epidermal cells of the elongation zone in Al-sensitive XZ9 was much higher than for the same tissues in XZ29 (Figure 7a, 7b). After $24 \mathrm{~h}, \mathrm{Al}$ accumulation decreased in the epidermal layer and stele of the elongation zone but increased in the cortex (Figure S10e,f). In the mature zone, Al accumulation clearly damaged epidermal cells of both genotypes but this occurred much earlier in XZ9 (after $24 \mathrm{~h}$ ) than that in XZ29 (after $72 \mathrm{~h}$ ) (Figure S10e-h). The fluxes of $\mathrm{HPO}_{4}{ }^{2-}$ from the elongation zone showed significant differences between XZ29 and XZ9. In the control, $\mathrm{HPO}_{4}{ }^{2-}$ efflux in XZ29 was larger than that in XZ9 (Figure 7c). The addition of $\mathrm{Al}$ transiently increased $\mathrm{HPO}_{4}{ }^{2-}$ efflux in XZ29 by $60 \%$ whereas no changes occurred in $\mathrm{XZ9}$. $\mathrm{HPO}_{4}{ }^{2-}$ efflux then decreased over time in both accessions.

\subsection{Al and $\mathrm{P}$ are co-localized in roots of Al-tolerant XZ29}

Since Morin dye may not be able to detect Al bound to cell wall (Eticha, Stass, \& Horst, 2005), further examination of the $\mathrm{Al}$ uptake and distribution over $72 \mathrm{~h}$ was applied using the SIMS technique. In the 
elongation zone, SIMS-detected $\mathrm{Al}$ accumulation increased gradually throughout the experiment (Figure S11a-h). Initial Al accumulation in the epidermal cells with XZ9 exhibited greater accumulation than that in XZ29 (Figure S11a,e). After $24 \mathrm{~h}, \mathrm{Al}$ was largely accumulated in the apoplast of the cortex (Figure $\mathrm{S} 11 \mathrm{c}, \mathrm{d}, \mathrm{g}, \mathrm{h})$. In the mature zone of XZ29, more $\mathrm{Al}$ was accumulated at the inner epidermal layer than the cortex (Figure 8a). We also detected the distribution of $\mathrm{P}$ in the mature tissues after $72 \mathrm{~h}$ and $\mathrm{P}$ levels were generally higher in XZ29 than in XZ9, especially in the stele and epidermis (Figure 8c,d). Interestingly, a strong $\mathrm{P}$ signal co-localized with $\mathrm{Al}$ at the inner layer of the epidermis (Figure 8a,c). Moreover, the same co-localization between $\mathrm{P}$ and $\mathrm{Al}$ was not detected for XZ9 despite this accession accumulating more $\mathrm{Al}$ in the cortex (Figure 8b,d).

\section{Discussion}

\subsection{Evolution of Al tolerance mechanisms in green plants}

$\mathrm{Al}$ comprises of $5 \%$ of mass in earth's crust, and it is the most common metallic element in the soil (Sposito, 2008). When and how did the green plants become adapted to Al-rich soil during plant terrestrialization? To answer this question, we conducted evolutionary and phylogenetic analysis of Al tolerance-associated predicted protein families to identify the origin of the Al-tolerance pathway. Many of these gene families were originated from streptophyte algae (Figure 1). Consistent with the recent work, it showed that the gene sequence identity and genetic similarity between streptophyte algae and land plants were significantly higher than those between streptophyte algae and chlorophyte algae (Liang et al., 2020; Zhao et al., 2019). It is proposed that streptophyte algae have generated key genetic innovations for the evolution of land plants in adaptation to terrestrial environment (Liang et al., 2020). In this study, the widely reported interactions between P and Al (Jiang et al., 2009; Liang et al.,2013; Sun et al., 2008; Zheng et al., 2005) led to the hypothesis that $\mathrm{Pi}$ homeostasis is crucial for plant $\mathrm{Al}$ tolerance. The high genetic similarity of many predicted protein families and large number of PHT1s and SPX-MFSs (Figures 2, S3-5) between streptophyte algae and bryophytes (hornwort/moss/liverwort) strongly suggested their potential significance during plant terrestrialization. Hornworts, liverworts and mosses, as three early diverging clades of land plants, occur in nearly all terrestrial habitats on all continents as pioneers in harsh environments such as acid soils (Blankenship, Condon, \& Pyke, 2019; Bowman et al., 2017; Zhang et al., 2020). Highly conserved glycolysis in land plants and streptophyte algae may have secured the energy to cope with Al toxicity, but this process was limited by Pi availability (Figures 4,5 ). These results provided first evidence for a conserved role of Pi homeostasis in land plants in adaptation to Al-rich acidic soil.

However, it does not mean that these proteins have conserved function between streptophyte algae and land plants or even between different plant species of the same clade in response to $\mathrm{Al}$ stress. For example, wheat TaALMT1 mediates the Al induced malate secretion in T. aestivum under Al stress (Sasaki et al., 2004), while the close homolog HvALMT1 in barley has no function in Al tolerance (Gruber et al., 2010). This is partially explained by the relatively low amino acid similarity in ALMTs family (Figures 1, S1; Table S3). Therefore, it was suggested that Al-induced secretion of organic acids (e.g. malate, citrate and oxalate) have gone through independent convergent evolution among different plant species (Ryan \& Delhaize, 2010). Moreover, cell wall functions as the first barrier for Al entry into the cytosol (Jones et al., 2006; Wu, Shen, Yokawa, \& Baluska, 2014), and PMEs and XTHs are key enzymes of cell wall modification in response to Al stress (Yang et al., 2008, Zhu et al., 2012). Our phylogenetic analysis indicated that these two protein families are originated from streptophyte algae (Figure 1). This is supported by the evidence that the evolvement of pectin-rich parental cell wall in streptophyte algae Zygogonium ericetorum helps its adaptation to acidic and high Al terrestrial habitats (Herburger et al., 2016).

\subsection{Al tolerance in XZ29 is associated with glycolysis and phosphate homeostasis}

Phosphate is a vital substrate in glycolysis and $\mathrm{P}$ deficiency leads to a sharp decrease in some sugar phosphates including Glu-6-P and Fru-6-P (Huang et al., 2008). Al-tolerant XZ29 showed higher level of the sugar phosphates than XZ9 under Al stress (Figure 5), thus facilitating relatively less inhibition of glycolysis pathway for normal root growth. Positive correlations between P-containing glycolytic intermediates and 
$\mathrm{P}$ concentration, and rapid recovery of these metabolites after $\mathrm{P}$ addition, suggests that the decrease of $\mathrm{P}$ and $\mathrm{Pi}$ concentrations during $\mathrm{Al}$ stress, especially in XZ9, caused the reduction of P-containing glycolytic intermediates (Figures 4, 5, 9). The higher activity of glycolysis in XZ29 could be associated with higher cytoplasmic Pi level. Why does XZ29 maintain higher cytoplasmic Pi level? Vacuolar Pi serves as a pool of Pi storage in plants (Pratt et al., 2009). SPX-MFS2 and SPX-MFS3 mediate Pi unloading from the vacuole into the cytosol (Wang et al., 2012; Wang et al., 2015). The up-regulation of HvSPX-MFS2and $H v S P X-M F S 3$ in XZ29 may mediate Pi transport from the vacuole to the cytosol, to supply Pi for glycolysis (Figures 6,9).

\section{3 $\mathrm{Pi}$ efflux detoxifies rhizosphere $\mathrm{Al}^{3+}$ and immobilization of $\mathrm{Al}$ with $\mathrm{P}$ in the epidermis confers Al tolerance in XZ29}

It was suggested that a constitutive efflux (Pellet, Papernik, \& Kochian, 1996) or leakage (Pettersson \& Strid, 1989) of $\mathrm{P}$ from roots contributed to Al-tolerance in wheat. However, those reports on Pi efflux at tissue level were not verified by subsequent investigations (Tang, Garvin, Kochian, Sorrells, \& Carver, 2002). In this study, we found Pi efflux/leakage occurred from root apices, a primary target of Al toxicity (Ryan, Shaff, \& Kochian, 1992; Ryan, Ditomaso, \& Kochian 1993), and mostly from the elongation zone (Figure 7c). The high cytosolic Pi availability in XZ29 provides sufficient stored Pi for Pi efflux/leakage. We propose that this rapid efflux/leakage of $\mathrm{Pi}$ could bind with $\mathrm{Al}^{3+}$, reducing $\mathrm{Al}$ uptake into the cytosol (Figure 9). This is partially supported by the fact that XZ29 accumulated less Al in the epidermis at the elongation zone than XZ9 (Figure 7a,b). However, the candidate transporters or ion channels responsible for the Pi efflux/leakage need be further studied.

Immobilization of $\mathrm{Al}$ by $\mathrm{P}$ in cell walls was previously linked with $\mathrm{Al}$ tolerance in buckwheat (Fagopyrum esculentum ) (Zheng et al., 2005), although other more established mechanisms contribute to the high $\mathrm{Al}$ tolerance of this species (Ma, Zheng, Matsumoto, \& Hiradate, 1997; Ma et al., 2001). In our study, we found the co-localization of $\mathrm{Al}$ and $\mathrm{P}$ in the inner epidermal layer (cell wall and apoplast) of root mature zone in XZ29, strongly suggesting the formation of Al-P complex (Figure 8). It is reported that binding Al with vital components of cell wall, such as pectin and semicellulose, reduced the flexibility of cell wall, leading to the rupturing of the rhizodermis and outer cortex and inhibition of the root elongation (Kopittke, Menzies, Wang, \& Blamey, 2016). Immobilization $\mathrm{Al}$ with large quantity of avaliable $\mathrm{P}$ may reduce the binding $\mathrm{Al}$ with pectin and semicellulose, thereby alleviating the Al stress on the structure and function of the cell wall in XZ29.

\subsection{Is $\mathrm{P}$ metabolism an evolutionary and ecological feature in Tibetan wild barley for its adaptation to acid soil?}

The major center of origin for barley is the Middle East which is mainly characterized by non-acid soils (Figure 10a,b). Most acid soils are often deficient in P (Kochian, 1995), thus it seems unlikely that plants would acquire an Al-tolerance mechanism that relies on releasing an essential and scarce macro-nutrient like P from their roots. However, Tibetan wild barley and domesticated Qingke barley are widely distributed and cultivated in the southeast regions of Tibet which has acidic soils with high total soil P (Figure 10b; Wang et al., 2008). It is worth noting that $\mathrm{P}$ concentration in root was positively correlated with $\mathrm{Al}$ tolerance, while $\mathrm{Al}$ concentration was negatively correlated with $\mathrm{Al}$ tolerance in 12 Tibetan wild barley accessions (Figure 10c,d). It is not unexpected that Tibetan wild barley has evolved unique mechanisms to adapt to these acidic and high $\mathrm{P}$ soil conditions. A plentiful supply of soil $\mathrm{P}$ facilitates the Al-induced Pi transport and metabolism in the Tibetan wild barley accession XZ29. We propose that Al tolerance in XZ29 relies on a new mechanism that high cytosolic Pi availability and Al-induced Pi efflux from root apexes (Figure 9). The phosphate release from roots was largely restricted to the elongation zone of root (Figure 7c), so its drain on plant nutrition could be minimal while protecting the root apices. Furthermore, Pi efflux from plant roots is a natural behavior in P homeostasis (Elliott, Lynch, \& Lauchli, 1984; Cogliatti \& Santa Maria, 1990), and other plant species well-supplied with P exhibit larger Pi efflux than plants deficient in P (Pettersson \& Strid, 1989; Cogliatti \& Santa Maria, 1990; Chen et al., 2012). Therefore, we conclude that Tibetan wild barley have developed an $\mathrm{Al}$ tolerance mechanism based on phosphate efflux from vacuole and phosphate 
release from the root apices which suited the low $\mathrm{pH}$ and high $\mathrm{P}$ soils on the Tibetan plateau.

\section{Acknowledgments}

We thank Dr Peter Ryan (CSIRO) for critical reading of the manuscript. We thank Prof. Dongfa Sun of Huazhong Agricultural University for providing Tibetan wild barley accessions. We thank Western Sydney University for providing the SIMS and Confocal Bio-imaging facility. Lijuan Mao and Zhiwei Ge (Zhejiang University) and Linda Westmoreland, Dr Sumedha Dharmaratne, Dr Anya Sali, and David Randall (Western Sydney University) for technical assistance. This work is supported by Natural Science Foundation of China (31771687). S.C is supported by Kuayue Project in Collage of Agriculture and Biotechnology, Zhejiang University. Z.H.C is supported by an Australian Research Council (ARC) Discovery Early Career Researcher Award (DE1401011143) and Horticulture Innovation Australia (VG17003; LP18000).

\section{Authors' contributions}

ZHC and GZ designed research; SC, YH, and LW conducted the bulk of experiments with assistance from RL, MZ and DW; ZHC and GZ supervised the experiments; SC, YH, LW and RL analyzed data; SC and ZHC wrote the article with contributions of all the authors.

\section{Conflict of Interest Statement}

The authors declare that they have no Conflict of Interest.

\section{References}

Blankenship, W. D., Condon, L. A., \& Pyke, D. A. (2020). Hydroseeding tackifiers and dryland moss restoration potential. Restoration Ecology . https://doi.org/10.1111/rec.12997.

Bowman, J. L., Kohchi, T., Yamato, K. T., Jenkins, J., Shu, S., Ishizaki, K., .. \& Adam, C. (2017). Insights into land plant evolution garnered from the Marchantia polymorpha genome. Cell, 171(2), 287-304.

Cai, S. G., Chen, G., Wang, Y., Huang, Y., Marchant, D. B., Wang, Y., .. \& \& Chen, Z. H. (2017). Evolutionary conservation of ABA signaling for stomatal closure. Plant Physiology, 174(2), 732-747.

Cai, S. G., Wu, D. H., Jabeen, Z., Huang, Y. Q., Huang, Y. C., \& Zhang, G. P. (2013). Genome-wide association analysis of aluminum tolerance in cultivated and Tibetan wild barley. PLoS ONE , 8, e69776.

Cardoso, T. B., Pinto, R. T., \& Paiva L. V. (2019). Analysis of gene co-expression networks of phosphate starvation and aluminium toxicity responses in Populus spp. PLoS ONE , 14(10), e0223217.

Chen, R. F., Zhang F. L., Zhang, Q. M., Sun, Q. B., Dong, X. Y., \& Shen, R. F. (2012). Aluminiumphosphorus interactions in plants growing on acid soils: does phosphorus always alleviate aluminium toxicity? Journal of the Science of Food and Agriculture , 92, 995-1000.

Chen, Z. H., Chen, G., Dai, F., Wang, Y., Hills, A., Ruan, Y. L., .. \& \& Blatt, M. R. (2017). Molecular Evolution of Grass Stomata.Trends in Plant Science, 22, 124-139.

Chen, Z. H., Pottosin, I. I., Cuin, T. A., Fuglsang, A. T., Tester, M., Jha, D., . \& \& Shabala S. (2007). Root plasma membrane transporters controlling $\mathrm{K}^{+} / \mathrm{Na}^{+}$homeostasis in salt-stressed barley. Plant Physiology , $145,1714-1725$.

Cogliatti, D. H., \& Santa Maria, G. E. (1990). Influx and efflux of phosphorus in roots of wheat plants in non-growth-limiting concentrations of phosphorus. Journal of Experimental Botany, 41, 601-607.

Dai, F, Chen, Z. H., Wang, X. L., Li, Z. F., Jin, G. L., Wu, D. Z., . . \& Zhang, G. P. (2014). Transcriptome profiling reveals mosaic genomic origins of modern cultivated barley. Proceedings of the National Academy of Sciences of the United States of America , 111, 13403-13408.

Dai, F., Nevo, E., Wu, D. Z., Comadran, J., Zhou, M. X., Qiu, L., .. \& Z Zhang, G. P. (2012). Tibet is one of the centers of domestication of cultivated barley. Proceedings of the National Academy of Sciences of the 
United States of America, 109, 16969-16973.

Dai, H. X., Cao, F. B., Chen, X. H., Zhang, M., Ahmed, I. M., Chen, Z. H., .. \& Wu, F. B. (2013). Comparative proteomic analysis of aluminum tolerance in Tibetan wild and cultivated barleys. PLoS ONE , 8, e63428.

Dai, H. X., Shan, W. N., Zhao, J., Zhang, G. P., Li, C. D., \& Wu, F. B. (2011). Difference in response to aluminum stress among Tibetan wild barley genotypes. Journal of Plant Nutrition and Soil Science, 174, 952-960.

Du, Y. M., Tian, J., Liao, H., Bai, C. J., Yan, X. L., Liu, G. D. (2009). Aluminium tolerance and high phosphorus efficiency helps Stylosanthes better adapt to low-P acid soils. Annals of Botany , 103(8), 12391247.

Elliott, G. C., Lynch, J., \& Lauchli, A. (1984). Influx and efflux of P in roots of intact maize plants double-labeling with P-32 and P-33.Plant Physiology , 76, 336-341.

Eticha, D., Stass, A., \& Horst, W. J. (2005). Localization of aluminium in the maize root apex: can morin detect cell wall-bound aluminium? Journal of Experimental Botany , 56, 1351-1357.

Feng, X., Liu, W., Qiu, C. W., Zeng, F., Wang, Y., Zhang, G., .. \& \& Wu, F. (2020) HvAKT2 and HvHAK1 Confer Drought Tolerance in Barley through Enhanced Leaf Mesophyll H+ Homeostasis. Plant Biotechnology Journal, http://doi: 10.1111/pbi.13332

Fujii, M., Yokosho, K., Yamaji, N., Saisho, D., Yamane, M., Takahashi, H., .. \& Ma, J. F. (2012). Acquisition of aluminium tolerance by modification of a single gene in barley. Nature Communications , 3, $132-136$.

Furukawa, J., Yamaji, N., Wang, H., Mitani, N., Murata, Y., Sato, K., .. \& Ma, J. F. (2007). An aluminum-activated citrate transporter in barley. Plant and Cell Physiology , 48, 1081-1091.

Ganjali, M. R., Mizani, F., \& Salavati-Niasari, M. (2003). Novel monohydrogenphosphate sensor based on vanadyl salophen. Analytica Chimica Acta , 481, 85-90.

Gruber, B. D., Ryan, P. R., Richardson, A. E., Tyerman, S. D., Ramesh, S., Hebb, D. M., .. \& Delhaize, E. (2010). HvALMT1 from barley is involved in the transport of organic anions. Journal of Experimental Botany , 61(5), 1455-1467.

Hassler, S., Lemke, L., Jung, B., Mohlmann, T., Kruger, F., Schumacher, K., .. \& Neuhaus, H. E. (2012). Lack of the Golgi phosphate transporter PHT4;6 causes strong developmental defects, constitutively activated disease resistance mechanisms and altered intracellular phosphate compartmentation in Arabidopsis. Plant Journal , 72, 732-744.

Herburger, K., Remias, D. \& Holzinger, A. (2016). The green algaZygogonium ericetorum (Zygnematophyceae, Charophyta) shows high iron and aluminium tolerance: protection mechanisms and photosynthetic performance. FEMS microbiology ecology, 92(8), fiw103.

Hossain, M., Zhou, M. X., \& Mendham, N. J. (2005). Reliable screening system for aluminium tolerance in barley cultivars. Australian Journal of Agricultural Research , 56, 475-482.

Huang, C. Y., Roessner, U., Eickmeier, I., Genc, Y., Callahan, D. L., Shirley, N., .. \& Bacic, A. (2008). Metabolite profiling reveals distinct changes in carbon and nitrogen metabolism in phosphate-deficient barley plants (Hordeum vulgare L.).Plant and Cell Physiology , 49, 691-703.

IGBP-DIS. (1998). SoilData(V.0) A program for creating global soil-property databases, IGBP Global Soils Data Task, France.

Jiang, H. X., Tang, N., Zheng, J. G., Lie, Y., \& Chen, L. S. (2009). Phosphorus alleviates aluminum-induced inhibition of growth and photosynthesis in Citrus grandis seedlings. Physiologia Plantarum, 137, 298-311. 
Jones, D. L., Blancaflor, E. B., Kochian, L. V., \& Gilroy, S. (2006). Spatial coordination of aluminium uptake, production of reactive oxygen species, callose production and wall rigidification in maize roots.Plant Cell and Environment , 29, 1309-1318.

Klug, B., Specht, A., \& Horst, W. J. (2011). Aluminium localization in root tips of the aluminiumaccumulating plant species buckwheat (Fagopyrum esculentum Moench). Journal of Experimental Botany, $62,5453-5462$.

Kobayashi, Y., Ohyama, Y., Kobayashi, Y., Ito, H., Iuchi, S., Fujita, M., .. \& Koyama, H. (2014). STOP2 activates transcription of several genes for Al- and low pH-tolerance that are regulated by STOP1 in Arabidopsis. Molecular Plant, 7(2), 311-322.

Kochian, L. V. (1995). Cellular mechanisms of aluminum toxicity and resistance in plants. Annual Review of Plant Physiology and Plant Molecular Biology , 46, 237-260.

Kochian, L. V., Hoekenga, O. A., \& Pineros, M. A. (2004). How do crop plants tolerate acid soils? Mechanisms of aluminum tolerance and phosphorous efficiency. Annual Review of Plant Biology , 55, 459-493.

Kochian, L.V., Pineros, M. A., Liu, J. P., \& Magalhaes, J. V. (2015). Plant adaptation to acid soils: The molecular basis for crop aluminum resistance. Annual Review of Plant Biology , 66, 571-598.

Kopittke, P. M., Menzies, N. W., Wang, P., \& Blamey, F. P. C. (2016). Kinetics and nature of aluminium rhizotoxic effects: a review.Journal of Experimental Botany ,67(15), 4451-4467.

Kopittke, P. M., Moore, K. L., Lombi, E., Gianoncelli, A., Ferguson, B. J., Blamey, F. P. C., . . \& Tollenaere, A. (2015). Identification of the primary lesion of toxic aluminum in plant roots. Plant Physiology , 167, 1402-1411.

Lambers, H., Finnegan, P.M., Jost, R., Plaxton, W.C., Shane, M.W., \& Stitt, M. (2015). Phosphorus nutrition in Proteaceae and beyond.Nature Plants , 1(8), 1-9.

Leebens-Mack, J. H., Barker, M. S., Carpenter, E. J., Deyholos, M. K., Gitzendanner, M. A., Graham S. W., ... \& Wong, G. K. (2019). One thousand plant transcriptomes and the phylogenomics of green plants.Nature, 574, 679-685.

Liang, C., Pineros, M. A., Tian, J., Yao, Z., Sun, L., Liu, J., .. \& \& Hong, L. (2013). Low pH, aluminum, and phosphorus coordinately regulate malate exudation through GmALMT1 to improve soybean adaptation to acid soils. Plant Physiology , 161(3), 1347-1361.

Liang, Z., Geng, Y., Ji, C., Du, H., Wong, C. E., Zhang, Q., .. \& \& Yu, H. (2020). Mesostigma viride genome and transcriptome provide insights into the origin and evolution of Streptophyta. Advanced Science , 7, 1901850. https://doi.org/10.1002/advs.201901850.

Lisec, J., Schauer, N., Kopka, J., Willmitzer, L., \& Fernie, A. R. (2006). Gas chromatography mass spectrometry-based metabolite profiling in plants. Nature Protocols , 1, 387-396.

Liu, J. L., Yang, L., Luan, M. D., Wang, Y., Zhang, C., Zhang, B., .. \& Luan, S. (2015). A vacuolar phosphate transporter essential for phosphate homeostasis in Arabidopsis. Proceedings of the National Academy of Sciences of the United States of America, 112, E6571-E6578.

Ma, J. F., Ryan, P. R., \& Delhaize, E. (2001). Aluminium tolerance in plants and the complexing role of organic acids. Trends in Plant Science, 6, 273-278.

Ma, J. F., Zheng, S. J., Matsumoto, H., \& Hiradate, S. (1997). Detoxifying aluminium with buckwheat. Nature, 390, 569-570.

Nevo, E., Baum, B., Beiles, A., \& Johnson, D. A. (1998). Ecological correlates of RAPD DNA diversity of wild barley, Hordeum spontaneum, in the Fertile Crescent. Genetic Resources and Crop Evolution , 45(2), 151-159. 
Newman, I. A. (2001). Ion transport in roots: measurement of fluxes using ion-selective microelectrodes to characterize transporter function. Plant Cell and Environment, 24(1), 1-14.

Nishiyama, T., Sakayama, H., De Vries, J., Buschmann, H., Saint-Marcoux, D., Ullrich, K.K., .. \& Rensing, S. A. (2018). The Chara genome: secondary complexity and implications for plant terrestrialization. Cell, $174(2), 448-464$.

Pellet, D. M., Papernik, L. A., \& Kochian, L.V. (1996). Multiple aluminum-resistance mechanisms in wheat - Roles of root apical phosphate and malate exudation. Plant Physiology, 112, 591-597.

Pettersson, S., \& Strid, H. (1989). Initial uptake of aluminum in relation to temperature and phosphorus status of wheat (Triticum-Aestivum L) roots. Journal of Plant Physiology , 134, 672-677.

Pratt ,J, Boisson, A. M., Gout, E., Bligny, R., Douce, R., \& Aubert, S. (2009). Phosphate (Pi) starvation effect on the cytosolic $\mathrm{Pi}$ concentration and $\mathrm{Pi}$ exchanges across the tonoplast in plant cells: An in vivo P-31-nuclear magnetic resonance study using methylphosphonate as a Pi analog. Plant Physiology , 151, 1646-1657.

Prodhan, M. A., Finnegan, P. M., \& Lambers, H. (2019). How does evolution in phosphorus-impoverished landscapes impact plant nitrogen and sulfur assimilation? Trends in Plant Science , 24(1), 69-82.

Qiu, L., Wu, D. Z., Ali, S., Cai, S. G., Dai, F., Jin, X. L., .. \& \& Zhang, G. P. (2011). Evaluation of salinity tolerance and analysis of allelic function of HvHKT1 and HvHKT2 in Tibetan wild barley. Theoretical and Applied Genetics , 122, 695-703.

Rae, A. L., Cybinski, D. H., Jarmey, J. M., \& Smith, F. W. (2003). Characterization of two phosphate transporters from barley; evidence for diverse function and kinetic properties among members of the Pht1 family. Plant Molecular Biology, 53, 27-36.

Runge-Metzger A. (1995). In Phosphorus in the global environment: transfers, cycles and management. Wiley, New York. 27-42.

Ryan, P. R., \& Delhaize, E. (2010). The convergent evolution of aluminium resistance in plants exploits a convenient currency. Functional Plant Biology, 37, 275-284.

Ryan, P. R., Ditomaso, J. M., \& Kochian, L. V. (1993). Aluminum toxicity in roots - an investigation of spatial sensitivity and the role of the root cap. Journal of Experimental Botany, 44, 437-446.

Ryan, P. R., Shaff, J. E., \& Kochian, L. V. (1992). Aluminum toxicity in roots - Correlation among ionic currents, ion fluxes, and root elongation in aluminum-sensitive and aluminum-tolerant wheat cultivars. Plant Physiology , 99, 1193-1200.

Sasaki, T., Yamamoto, Y., Ezaki, B., Katsuhara, M., Ahn, S. J., Ryan, P. R., .. \& Matsumoto, H. (2004). A wheat gene encoding an aluminum-activated malate transporter. Plant Journal , 37, 645-653

Smart, K. E., Smith, J. A., Kilburn, M. R., Martin, B. G., Hawes, C., \& Grovenor, C. R. (2010). Highresolution elemental localization in vacuolate plant cells by nanoscale secondary ion mass spectrometry. Plant Journal , 63, 870-879.

Sposito, G. (2008). The chemistry of soils. Oxford university press.

Stefanovic, A., Arpat, A. B., Bligny, R., Gout, E., Vidoudez, C., Bensimon, M., \& Poirier, Y. (2011). Overexpression of PHO1 in Arabidopsis leaves reveals its role in mediating phosphate efflux.Plant Journal , 66, 689-699.

Sun, Q. B., Shen, R. F., Zhao, X. Q., Chen, R. F., \& Dong, X. Y. (2008). Phosphorus enhances Al resistance in Al-resistant lespedeza bicolor but not in Al-sensitive L. cuneata under relatively high $\mathrm{Al}$ stress. Annals of Botany , 102, 795-804. 
Tang, Y., Garvin, D. F., Kochian, L.V., Sorrells, M. E., \& Carver, B. F. (2002). Physiological genetics of aluminum tolerance in the wheat cultivar atlas 66. Crop Science, 42, 1541-1546.

Taylor, G. J., McDonald-Stephens, J. L., Hunter, D. B., Bertsch, P. M., Elmore, D., Rengel, Z., \& Reid, R. J. (2000). Direct measurement of aluminum uptake and distribution in single cells of Chara corallina.Plant Physiology, 123, 987-996.

Tokizawa, M., Kobayashi, Y., Saito, T., Kobayashi, M., Iuchi, S., Nomoto, M., .. \& Koyama, H. (2015). Sensitive to proton rhizotoxicity1, calmodulin binding transcription activator2, and other transcription factors are involved in aluminum-activated malate transporter1 expression. Plant Physiology , 167(3), 991-1003.

Urano, K., Kurihara, Y., Seki, M., \& Shinozaki, K. (2010). 'Omics' analyses of regulatory networks in plant abiotic stress responses. Current Opinion in Plant Biology , 13, 132-138.

Wang, C., Huang, W., Ying, Y.H., Li, S., Secco, D., Tyerman, S., .. \& \& Shou, H. X. (2012). Functional characterization of the rice SPX-MFS family reveals a key role of OsSPX-MFS1 in controlling phosphate homeostasis in leaves. New Phytologist, 196, 139-148.

Wang, C., Yue, W. H., Ying, Y. H., Wang, S. D., Secco, D., Liu, Y., .. \& \& Shou, H. X. (2015). Rice SPXMajor Facility Superfamily3, a vacuolar phosphate efflux transporter, is involved in maintaining phosphate homeostasis in rice. Plant Physiology, 169, 2822-2831.

Wang, J. P., Raman, H., Zhou, M. X., Ryan, P. R., Delhaize, E., Hebb, D. M., ... \& Mendham, N. (2007). High-resolution mapping of the Alp locus and identification of a candidate gene HvMATE controlling aluminium tolerance in barley (Hordeum vulgare L.). Theoretical and Applied Genetics, 115, 265-276.

Wang, S., Li, L., Li, H., Sahu, S. K., Wang, H., Xu, Y., . . \& Chang, Y. (2020). Genomes of early-diverging streptophyte algae shed light on plant terrestrialization. Nature Plants , 6, 95-106.

Wang, T., Yang, Y. H., \& Ma W. H. (2008). Storage, patterns and environmental controls of soil phosphorus in China. Acta Scientiarum Naturalium Universitatis Pekinensis , 44, 945-952.

Wu, D. M., Shen, H., Yokawa, K., \& Baluska, F. (2014). Alleviation of aluminium-induced cell rigidity by overexpression of OsPIN2 in rice roots. Journal of Experimental Botany , 65, 5305-5315.

Wu, D. Z., Cai, S. G., Chen, M. X., Ye, L. Z., Chen, Z. H., Zhang, H. T., . \& \& Zhang, G. P. (2013). Tissue metabolic responses to salt stress in wild and cultivated barley. PLoS ONE, 8, e55431.

Yang, J. L., Fan, W., \& Zheng, S. J. (2019). Mechanisms and regulation of aluminum-induced secretion of organic acid anions from plant roots. Journal of Zhejiang University-SCIENCE B , 20(6), 513-527.

Yang, J. L., Li, Y. Y., Zhang, Y. J., Zhang, S. S., Wu, Y. R., Wu, P., \& Zheng, S. J. (2008). Cell wall polysaccharides are specifically involved in the exclusion of aluminum from the rice root apex.Plant Physiology , 146(2), 602-611.

Yang, J. L., Zhu, X. F., Peng,Y. X., Zheng, C., Li, G. X., Liu, Y., .. \& Z Zheng S. J. (2011). Cell wall hemicellulose contributes significantly to aluminum adsorption and root growth in Arabidopsis. Plant Physiology ,155, 1885-1892.

Yang, Z. B., Geng, X., He, C., Zhang, F., Wang, R., Horst, W. J., \& Ding, Z. (2014). TAA1-regulated local auxin biosynthesis in the root-apex transition zone mediates the aluminum-induced inhibition of root growth in Arabidopsis. The Plant Cell , 26(7), 2889-2904.

Yang, Z. B., He, C., Ma, Y., Herde, M., \& Ding, Z. (2017). Jasmonic acid enhances Al-induced root growth inhibition. Plant Physiology, 173(2), 1420-1433.

Zhang, J., Fu, X. X., Li, R. Q., Zhao, X., Liu, Y., Li, M. H., .. \& Chen, Z. D. (2020). The hornwort genome and early land plant evolution. Nature Plants , 6(2), 107-118. 
Zhao, C., Wang, Y., Chan, K. X., Marchant, D. B., Franks, P. J., Randall, D., .. \& Zhang, B. (2019). Evolution of chloroplast retrograde signaling facilitates green plant adaptation to land.Proceedings of the National Academy of Sciences , 116(11), 5015-5020.

Zheng, S. J., Yang, J. L., He, Y. F., Yu, X. H., Zhang, L., You, J. F., .. \& Matsumoto, H. (2005). Immobilization of aluminum with phosphorus in roots is associated with high aluminum resistance in buckwheat. Plant Physiology , 138, 297-303.

Zhou, J., Jiao, F. C., Wu, Z. C., Li, Y. Y., Wang, X. M., He, X. W., .. \& Wu, P. (2008). OsPHR2 is involved in phosphate-starvation signaling and excessive phosphate accumulation in shoots of plants.Plant Physiology , 146, 1673-1686.

Zhu, X. F., Shi, Y. Z., Lei, G. J., Fry, S. C., Zhang, B. C., Zhou, Y. H., . . \& Zheng S. J. (2012). XTH31, Encoding an in vitro XEH/XET-active Enzyme, regulates aluminum sensitivity by modulating in vivo XET action, cell wall xyloglucan content, and aluminum binding capacity in arabidopsis. The Plant Cell , 24, 4731-4747.

\section{Supporting Information}

Figure S1. Average protein similarity of transporters in different plant clades.

Figure S2. Average protein similarity in different clades of gene families in different plant clades.

Figure S3. Phylogenetic tree of SPX-MFSs and PHT1s from algae to angiosperms

Figure S4. Conserved domains in SPX-MFSs.

Figure S5. Conserved domains in PHT1s.

Figure S6. Total root length of three barley genotypes in response to $\mathrm{Al}$ stress.

Figure S7. Metabolite profiles and metabolic pathways in root tip of barley XZ29 and XZ9 under Al treatment.

Figure S8. Correlation analysis of primary metabolites.

Figure S9. The effect of $\mathrm{P}$ addition on primary metabolites in barley root tips treated with $72 \mathrm{~h}$ of $\mathrm{Al}$ treatment.

Figure S10. Fluorescence imaging of Al distribution in root cross-sections of XZ29 and XZ9.

Figure S11. Secondary ion mass spectrometry (SIMS) of Al distribution in root elongation zone of XZ29 and XZ9. Al distribution in root elongation zone of XZ29 (a-d) and XZ9 (e-h) after 2, 6, 24, and $72 \mathrm{~h}$ of 5 $\mu \mathrm{M}$ Al treatments.

Table S1. Primers for PCR and qRT-PCR.

Table S2. List of gene families related with plant Al tolerance.

Table S3. Protein similarity of Al tolerance-associated genes/ gene families in 41 species of land plants and algae with $\mathrm{E}$ value $<10^{-5}$.

Table S4. Gene number of Al tolerance-associated genes/ gene families in 41 species of land plants and algae with $\mathrm{E}$ value $<10^{-5}$.

Table S5. Detection of the 1-kb insertion in HvAACT1 upstream region in 110 Tibetan wild barley accessions and a barley cultivar Dayton.

Table S6. The changes of primary metabolites in response to 6 to $72 \mathrm{~h}$ of Al treatments.

Table S7. The changes of primary metabolites in response to 2 to $24 \mathrm{~h}$ of $\mathrm{P}$ addition after $72 \mathrm{~h} \mathrm{Al}$ treatment. 
Table S8. Gene expression of Pi transporter genes in XZ-29 and XZ-9 after 0.5, 2, 6, 12 and $24 \mathrm{~h}$ of $5 \mu \mathrm{M}$ $\mathrm{Al}$ treatments.

\section{Figure legends}

Figure 1. Similarity heatmap of protein sequences of Al tolerance-associated genes/ gene families in 41 land plants and algae. The detailed information of these gene family was shown in Table S2. Colored squares indicate protein sequence similarity from zero (yellow) to $100 \%$ (red) and gray indicates no match of sequences in this species.

Figure 2. Phylogenetic tree of SPX-MFSs and PHT1s from algae to angiosperms. (a) SPX-MFSs; (b) PHT1s. The protein sequences were obtained from OneKP database. The protein sequences were aligned using MAFFT, and the conserved domains were generated using Gblocks software, and the maximum likelihood (ML) tree was constructed using FastTree and was displayed using iTOL.

Figure 3. Effect of $\mathrm{Al}$ on root growth, $\mathrm{Al}$ concentration, citrate secretion and HvAACT1 gene expression. (a) Images of seven-day-old seedlings of XZ29, XZ9, Dayton and Franklin grown on neutral soil (control) and acid soil ( $\mathrm{pH} 4.7 ; 13.6 \mathrm{mEq} / \mathrm{kg}$ exchangeable Al). (b) Root growth under $144 \mathrm{~h}$ of $5 \mu \mathrm{M}$ Al treatment. (c) Whole root $\mathrm{Al}$ concentration after $144 \mathrm{~h} \mathrm{Al}$ treatment. (d) Citrate secretion from excised root tips exposed to $2 \mathrm{~h}$ of $5 \mu \mathrm{M} \mathrm{Al}$ treatment. (e) HvAACT1 gene expression in root tips under $2 \mathrm{~h}$ of $5 \mu \mathrm{M} \mathrm{Al}$ treatment. (f) Gel electrophoresis of HvAACT1 with 1-kb sequence insertion in the upstream of coding region of Dayton. Data are means $\pm \mathrm{SE}(\mathrm{n}=3)$. Different lower case letters indicate significant difference at $\mathrm{P}<0.05$.

Figure 4. Primary metabolites in root tips of plants under Al treatments. (a) Heatmap of primary metabolites in root tips of XZ29 and XZ9 under Al treatment. Five blocks (for each metabolite and genotype) represent the changes of metabolite concentrations after $6,12,24,48$, and $72 \mathrm{~h}$ of $5 \mu \mathrm{M}$ Al treatments (from left to right) respectively. The color of block represents the change of metabolite concentrations, which is displayed as $\log _{2}$ transformed ratio of metabolite concentration under Al treatment to metabolite concentration under control condition (control was sampled at each time point). Dark red (value $=2$ ) represents that metabolite concentration in treatment is four-fold as that in control, while dark blue (value $=-2$ ) represents that the metabolite concentration in treatment is 0.25 -fold as that in control. Cluster analysis was performed using K-mean method by SPSS. Four biological replicates were used. (b) Temporal changes of metabolites and gene expressions in glycolytic pathway. In the line charts, y axis represents the $\log _{2}$ transformed ratio of metabolite concentration under $\mathrm{Al}$ treatment to metabolite concentration in the control (control plant was also sampled at each time point), and $\mathrm{x}$ axis represents the time of $\mathrm{Al}$ treatment. In the heatmap of gene expressions, five blocks represent the relative gene expression after $0.5,2,6,12$ and $24 \mathrm{~h}$ of $5 \mu \mathrm{M} \mathrm{Al}$ treatments. Green represents up-regulation and purple represents down-regulation. (c) Al-induced the change of primary metabolites in root tips of five plant species including Marchantia polymorpha, Ginkgo biloba, Medicago truncatula, Zea mays and Triticum aestivum. Gray block means that the metabolite was not detected in the sample. Glu-6-P, glucose-6-phosphate; Fru-6-P, fructose-6-phosphate; 3-PGA, 3-phosphoglyceric acid; 2-PGA, 2-phosphoglyceric acid; PEP, phosphoenolpyruvate; HXK, hexokinase; GPI, glucose-6-phosphate isomerase; PFK, 6-phosphofructokinase; PFP, fructose-6-phosphate 1-phosphotransferase; FBA, fructose bisphosphate aldolase; TIM, triosephosphate isomerase; GAPDH, glyceraldehyde-3-phosphate dehydrogenase; PGK, Phosphoglycerate kinase; Enolase, enolase; PK, pyruvate kinase.

Figure 5. The effect of $\mathrm{P}$ and $\mathrm{Pi}$ on $\mathrm{P}$-containing glycolytic intermediates under $\mathrm{Al}$ stress. (a, b) Relative $\mathrm{P}$ and Pi concentrations in root tips after 2, 6, 24, and $72 \mathrm{~h} \mathrm{Al}$ treatments. (c) Correlation analysis between $\mathrm{P}$-containing glycolytic intermediates and root tip $\mathrm{P}$ and $\mathrm{Pi}$ concentrations. The glycolytic intermediates, $\mathrm{P}$ and $\mathrm{Pi}$ concentrations under 6, 24, and $72 \mathrm{~h}$ of $\mathrm{Al}$ treatments were used. (d) Temporal changes of Pcontaining glycolytic intermediates in response to 2,6,12 and $24 \mathrm{~h}$ of $\mathrm{P}$ addition after $72 \mathrm{~h} \mathrm{Al}$ treatment. Data are means $\pm \mathrm{SE}(\mathrm{n}=3-4) .{ }^{*} \mathrm{P}<0.05,{ }^{* *} \mathrm{P}<0.01$.

Figure 6. Effect of Al treatments on the expression of Pi transporter/signaling genes in XZ29 and XZ9. Gene expression of Pi transporters/signaling in root tips after $0.5,2,6,12$, and $24 \mathrm{~h}$ of $5 \mu \mathrm{M} \mathrm{Al}$ treatments. Data are means $\pm \mathrm{SE}\left(\mathrm{n}=4\right.$ biological replicates). ${ }^{*}$ represents significant difference between genotypes at 
$\mathrm{P}<0.05$

Figure 7. Al-morin fluorescence and Al-induced root $\mathrm{HPO}_{4}{ }^{2-}$ flux in root elongation zone in XZ29 and XZ9. (a, b) Al-morin fluorescence imaging of $\mathrm{Al}$ distribution in the cross-sections of root elongation zone after 6 $\mathrm{h} \mathrm{Al}$ treatment. A total of 6-8 replicates were performed for each genotype, and the representative images were shown. Scale bars: $50 \mu \mathrm{m}$. (c) Al-induced root $\mathrm{HPO}_{4}{ }^{2-}$ flux of XZ29 and XZ9. The $\mathrm{HPO}_{4}{ }^{2-}$ flux was determined when plants (three-day-old seedling) incubated in MIFE basal solution $(500 \mu \mathrm{M} \mathrm{KCl}$ and 100 $\mu \mathrm{M} \mathrm{CaCl} 2$ with $\mathrm{pH} 4.3)$. Average Al-induced net $\mathrm{HPO}_{4}{ }^{2-}$ fluxes in the control (0-10 min), transient (11 to $15 \mathrm{~min}$ ) and steady-state (30-40 min) were measured from elongation zone response to $25 \mu \mathrm{M} \mathrm{Al}$ treatment. Influx (uptake) of the ions has a positive sign and efflux (release) has a negative sign. Data are means $\pm \mathrm{SE}$ ( $\mathrm{n}=6-10$ biological samples). ${ }^{*}$ represents significant difference at $\mathrm{P}<0.05$.

Figure 8. Secondary ion mass spectrometry (SIMS) of $\mathrm{Al}$ and $\mathrm{P}$ distribution in cross-sections of root mature zone in XZ29 and XZ9. Al and P distribution in root mature zone of XZ29 (a, c) and XZ9 (b, d) after $72 \mathrm{~h}$ of $5 \mu \mathrm{M} \mathrm{Al}$ treatment. Shown are representative images $(\mathrm{n}=4-6)$. Scale bars: $50 \mu \mathrm{m}$.

Figure 9. Putative schematic diagram of cellular $\mathrm{P}$ transport and metabolism in Tibetan wild barley XZ29 under $\mathrm{Al}$ stress. $\mathrm{Al}^{3+}$ enters into the cell, and binds with $\mathrm{PO}_{4}{ }^{3-}$ to form Al-P complex. This decreased the cytosolic Pi level, resulting in reduction of P-containing glycolytic intermediates and inhibition of glycolysis. Cytosolic P deficiency activates $\mathrm{Pi}$ efflux from vacuole to cytosol probably mediated by the tonoplast $\mathrm{Pi}$ efflux transporters SPX-MFS2/3, to enhance the cytosolic Pi level. Immobilization of $\mathrm{Al}$ with $\mathrm{P}$ in the cell wall or apoplast is observed. Al treatment induces a transient Pi efflux from root to chelate the rhizosphere $\mathrm{Al}^{3+}$. However, the transporter or ion channel is unknown.

Figure 10. Linking soil acidity and total soil phosphorus $(\mathrm{P})$ in centers of barley origin (Near East and Tibetan Plateau) to Al and P concentration in Tibetan wild barley under Al stress. (a) Southern and southeastern Tibetan plateau has acidic soil (green box) and Near East has alkaline soil (pink box). Source http://nelson.wisc.edu/sage/data-and-models/atlas. (b) P distribution in China. Southern and southeastern Tibetan plateau has high total soil P (green box) (Wang et al., 2008). (c, d) correlation analysis between relative root growth and $\mathrm{Al}$ and $\mathrm{P}$ content in 12 Tibetan wild barley accessions under $\mathrm{Al}$ stress. ${ }^{*} \mathrm{P}<0.05,{ }^{* *} \mathrm{P}<0.01$.

\section{Hosted file}

Cai et al 2020 Figures Final.pdf available at https://authorea.com/users/300612/articles/ 430317-evolution-of-phosphate-metabolism-and-the-adaptation-of-tibetan-wild-barley-toaluminum-stress 


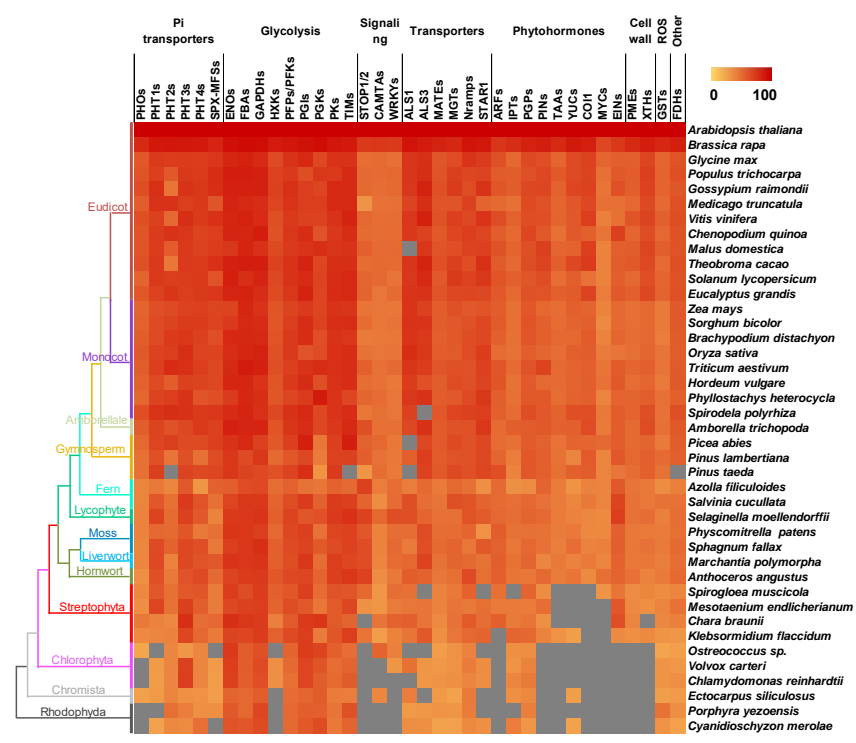

Figure 1. Similarity heatmap of protein sequences of Al tolerance-associated genes/ gene families in 41 land plants and algae. The detailed information of these gene family was shown in Table S2. Colored squares indicate protein sequence similarity from zero (yellow) to $100 \%$ (red) and gray indicates no match of sequences in this species. 